\title{
The Effects of Mortality, Subsistence, and Ecology on Human Adult Height and Implications for Homo Evolution
}

\author{
by Andrea Bamberg Migliano and Myrtille Guillon
}

CA+ Online-Only Material: Supplement A

The increase in body size observed with the appearance and evolution of Homo is most often attributed to thermoregulatory and locomotor adaptations to environment; increased reliance on animal protein and fat; or increased behavioral flexibility, provisioning, and cooperation leading to decreased mortality rates and slow life histories. It is not easy to test these hypotheses in the fossil record. Therefore, understanding selective pressures shaping height variability in living humans might help to construct models for the interpretation of body size variation in the hominins. Among human populations, average male height varies extensively $(145 \mathrm{~cm}-183 \mathrm{~cm})$; a similar range of variation is found in Homo erectus (including African and Georgian samples). Previous research shows that height in human populations covaries with life history traits and variations in mortality rates and that different environments affect adult height through adaptations related to thermoregulation and nutrition. We investigate the interactions between life history traits, mortality rates, environmental setting, and subsistence for 89 small-scale societies. We show that mortality rates are the primary factor shaping adult height variation and that people in savanna are consistently taller than people in forests. We focus on relevant results for interpreting the evolution of Homo body size variability.

Body size is one of the major features that distinguishes australopiths from early Homo and early Homo from Homo erectus (Antón 2012; Holliday 2012; Pontzer 2012). Some of the most important questions about the evolution of Homo concern the reasons behind the observed size increase between these taxa and the variation within them.

Paleoanthropologists have offered a number of hypotheses for body size increase in hominins. For example, Wheeler (1992) proposed that body size and body proportions were specific thermoregulatory adaptations to the environments encountered by the hominins, as have Vrba (1996), Passey et al. (2010), and Trauth et al. (2010). A number of authors also have related diet to increased body size (e.g., Aiello and Wheeler 1995; Carmody and Wrangham 2009). And O'Connell, Hawkes, and Blurton Jones (1999) argue that the evolution of larger body size in $H$. erectus was originally as-

\footnotetext{
Andrea Bamberg Migliano is Lecturer in Evolutionary Anthropology in the Department of Anthropology at University College London (14 Taviton Street, London WC1H 0BW, U.K. [a.migliano@ucl.ac .uk]). Myrtille Guillon is a graduate student in the Department of Anthropology at University College London (Gower Street, London WC1E 6BT, U.K). This paper was submitted 12 XII 11, accepted 9 VII 12 , and electronically published 27 XI 12.
}

sociated with reduced mortality rates (associated with increased alloparenting) in comparison with earlier members of Homo and australopithecines.

These hypotheses are largely mutually exclusive, and the explanation for size variation in the hominins undoubtedly involves a complex interaction between such factors as climate, mortality rates, and nutrition. By building a detailed understanding of the causes of body size differences in modern human populations, we believe that we will be in a much stronger position to generate testable hypotheses for body size changes during hominin evolution.

In modern humans there is good evidence of the relationship between body size and climate. For example, Roberts (1973) demonstrated body size increase with distance from the equator. Size variation has also been linked directly to thermoregulatory adaptations. Specifically, smaller body size (both in height and weight) may help to reduce heat production in hot and humid environments (Cavalli-Sforza 1986) while larger bodies may help to conserve heat in cold environments (Bergmann 1847), a pattern that is generally found among other mammals (Ashton, Tracy, and de Queiroz 2000). With the publication of Charnov's (1992) general life history model, growing attention has been directed to mortality risk as a factor potentially shaping body size evolution. As 
death restricts the amount of time available to an organism, time and energy invested into one process (growth, reproduction, and maintenance) cannot be invested in another. In other words, not all processes can be simultaneously maximized (Charnov 1992; Stearns 1992). Because larger individuals tend to have a higher energy capture rate during growth and thus a higher production rate at adulthood and a higher energy budget to be invested into reproduction (Stearns 1992), more time allotted to growth (i.e., late maturation) will tend to be favored. However, there are potential costs to delaying maturation as it increases the likelihood of death before reproduction. For this reason, low mortality rates favor delayed maturation and large body size, and high mortality favors earlier reproduction and growth termination and hence small body size. For this reason, mortality rates are likely to determine the pace of life histories, the balance of investment in growth versus reproduction, and variation in adult body size (Harvey and Clutton-Brock 1985; Harvey and Purvis 1999; Harvey and Zammuto 1985; Promislow and Harvey 1990).

This general relationship between mortality and growth should influence body size variability not only across taxa but also among human populations (Adair 2007; Kuzawa and Bragg 2012; Migliano, Vinicius, and Lahr 2007; Walker et al. 2006). One example of this relationship in humans is the short stature of Pygmies, which we found to be best explained as a consequence of an accelerated life history (early growth cessation) caused by high mortality rates in a nutritionally stressful environment (Migliano 2005; Migliano, Vinicius, and Lahr 2007, 2010; Stock and Migliano 2009).

Diet and nutrition are also important factors affecting growth and consequently adult height in modern humans (Bailey 1991; Golden 1991). For example, malnourished children suffering from protein or calorie deficiency grow slowly, delay maturation, and achieve shorter stature (Akachi and Canning 2007; Cameron 1991; Danubio and Sanna 2008; Lampl, Johnston, and Malcolm 1978; Silventoinen 2003). Interestingly, these factors affect adult body size through different mechanisms; while malnourishment will lead to slower growth rates and delayed maturation (Lampl, Johnston, and Malcolm 1978), increased adult mortality rates should lead to the acceleration of growth rates and earlier maturation (Migliano, Vinicius, and Lahr 2007; Walker et al. 2006).

What is the effect of adult mortality rates, rates of growth and maturation, subsistence strategies, and variation in environmental settings on current human height diversity? We analyze a cross-cultural database that includes 89 living human populations of foragers, small-scale farmers, horticulturalists, and pastoralists living in varying environments from forests to deserts (see $\mathrm{CA}+$ online supplement A). We then discuss the applications of our findings to the hominin fossil record and propose testable hypotheses for explaining the variation in body size observed in the genus Homo.

\section{Material and Methods}

We use a compiled database that includes information on the life histories of 89 small-scale human populations. Part of the data was obtained from the Comparative Human Life History Spreadsheet, ${ }^{1}$ with part of the data previously published in Migliano, Vinicius, and Lahr (2007) and Walker et al. (2006). We supplement this database with data from other ethnographic sources that provide information about average stature, age at menarche, and survival to age 15 in traditional small-scale societies. All populations are classified according to their primary environment using relevant ethnographic literature (supplement A).

Most mortality data were obtained from Walker et al. (2006), which describes data quality. Populations were selected for inclusion on the basis of two specific criteria; only traditional small-scale societies were sampled, and populations that had experienced recent significant changes in lifestyle were excluded.

Dietary variables were taken from Binford (2001), who described the diet of hunter-gatherer populations in terms of percentage of food coming from hunting (percentage of reliance on hunting), from fishing (percentage of reliance on fishing), and from gathering (percentage of reliance on gathering). We use these data to estimate the effects of reliance on animal protein (increased meat and fish in the diet) on hunter-gatherers' size variation.

There are several limitations to this cross-cultural approach. First, the fact that different measurements have been taken by different people at different times with variable sample sizes potentially introduces a number of sources of error. Second, the demographic indicators of mortality (survival to age 15, life expectancy at birth, and life expectancy at age 15) are derived primarily from retrospective interviews but in some cases are inferred from stable population models. Third, dietary percentages rely on the quality of the data obtained for each population (see Binford 2001 for a description of the subsistence data). Nonetheless, if we are to understand how different ecological and demographic variables affect variation in human body size worldwide, it is necessary to rely on cross-cultural samples. Here, we have done our best to ensure compatibility of the data and present the results of this analysis as hypotheses to stimulate further work in this area.

To test data quality, we analyzed subsets of the data as well as the entire data set. The results were very similar in all analyses. For example, we regressed adult body size on probability of survival to age 15 controlling for continent, sex, and environment for the total data set $(n=42)$ and only for the hunter-gatherer sample $(n=29)$. In both samples survival at age 15 had a significant positive effect on adult height, and people in the savanna were significantly taller than people in the forest (comparisons not shown).

1. http://dice.missouri.edu. 
Table 1. Linear regression models using life expectancy at birth, life expectancy at age 15, and probability of survival to age 15 to predict adult height

\begin{tabular}{|c|c|c|c|c|c|c|c|}
\hline \multirow[b]{2}{*}{ Predictor } & \multicolumn{3}{|c|}{$\begin{array}{l}\text { Whole model (including sex, continent, } \\
\text { and one of the three mortality } \\
\text { predictors) }\end{array}$} & \multicolumn{2}{|c|}{$\begin{array}{l}\text { Last block (change) } \\
\text { when including } \\
\text { one of the three } \\
\text { mortality predictors }\end{array}$} & \multicolumn{2}{|c|}{$\begin{array}{l}\text { Partial correlation and standardized } \\
\beta \text { coefficient (controlling for } \\
\text { sex and continent) }\end{array}$} \\
\hline & $R$ & $R^{2}(\mathrm{SE})$ & ANOVA $(P)$ & $R_{\text {change }}^{2}$ & $F_{\text {change }}(P)$ & Partial correlation & Standardized $\beta(P)$ \\
\hline $\begin{array}{l}\text { Life expectancy at birth } \\
\quad(n=19)\end{array}$ & .787 & $.620(.017)$ & $F=4.24(.001)$ & .253 & $8.66(.011)$ & .632 & $.593(.011)$ \\
\hline $\begin{array}{l}\text { Life expectancy at age } 15 \\
\quad(n=19)\end{array}$ & .843 & $.711(.015)$ & $F=6.38(.003)$ & .336 & $15.06(.002)$ & .733 & $.649(.002)$ \\
\hline $\begin{array}{l}\text { Probability of survival to } \\
\text { age } 15(n=42)\end{array}$ & .755 & $.570(.017)$ & $F=6.43(<.001)$ & .299 & $23.6(<.001)$ & 640 & $.592(<.001)$ \\
\hline
\end{tabular}

Least squares multiple regression models are employed to assess the extent to which estimates of mortality (life expectancy at birth, life expectancy at age 15, and survival to age 15) and diet predict human height. In order to include the effect of the primary environment in the analysis, dummy variables were created for each environment type and subsistence strategy. The primary environments are categorized as forest, savanna, desert, and tundra. When dummy variables are included in a regression model, stepwise methods become inappropriate, and so the enter method was used. To control for the nonindependence of human societies as statistical points that can arise because of phylogenetic history, populations were classified according to their continents, and this variable was used as a control in the regression analyses. This was considered appropriate because our sample involves isolated populations that have a long tradition of life in their current geographical settings. Bivariate correlation analyses are used to investigate relationships between life history variables and body size. We control for sex when males and females from different populations were entered in the same analyses and when the analyses included populations for which male and female variables had been calculated together in the original publications. We used log transformation when normality transformations were required. All regression, correlation, and variance analyses were produced using PASW 18 (SPSS, Chicago).

\section{Results}

Five separate sets of multiple regression analysis are carried out. The first two focus on mortality rate and its relationship to adult height variation and to growth and development. The second two focus on environmental setting and its relationship to adult height variation and to both mortality rate and adult height variation. The last analysis looks at the relationship between subsistence strategy and adult height and life history diversity. The major result emerging from these analyses is that measures of mortality (or survivorship) are the prime determinate in adult height in the sample of smallscale human populations, although environmental setting also has a significant influence.

\section{Analysis I: Relationship between Mortality Rate and Adult Height Variation}

In separate multiple regression analyses including sex and continent, three different measures of mortality/survivorship each show a significant correlation with adult height, population average life expectancy at birth $\left(n=19, R^{2}=0.620\right.$, $P<.001)$, life expectancy at age $15\left(n=19, R^{2}=0.711\right.$, $P<.001)$, and the probability of survival to age $15(n=42$, $R^{2}=0.570, P<.001$; table 1$)$. The fact that life expectancy at age 15 is strongly correlated with adult height suggests that mortality rates in adulthood affect adult stature.

Controlling for sex and continent, life expectancy at birth is a strong predictor of adult height $(\beta=0.593, P=.011)$, explaining an extra $25.3 \%$ of the variance in height in relation to what is explained only by continent and sex. When the probability of survival to age 15 is used to predict adult height, the relationship is very similar to that with life expectancy at birth $(\beta=0.592, P<.001)$, with an extra $29.9 \%$ of the variance explained in relation to the basal model (which includes sex

Table 2. Linear regression model using probability of survival to age 15 to predict relative height at age 10

\begin{tabular}{|c|c|c|c|c|c|c|c|}
\hline \multirow[b]{2}{*}{ Predictor } & \multicolumn{3}{|c|}{$\begin{array}{l}\text { Whole model (including sex, continent, } \\
\text { and probability of survival to age 15) }\end{array}$} & \multicolumn{2}{|c|}{$\begin{array}{l}\text { Last block (change) } \\
\text { when including } \\
\text { probability of } \\
\text { survival to age } 15 \\
\end{array}$} & \multicolumn{2}{|c|}{$\begin{array}{l}\text { Partial correlation and standardized } \\
\beta \text { coefficient (controlling for } \\
\text { sex and continent) }\end{array}$} \\
\hline & $R$ & $R^{2}(\mathrm{SE})$ & ANOVA $(P)$ & $R^{2}$ & $F(P)$ & Partial correlation & Standardized $\beta(P)$ \\
\hline $\begin{array}{l}\text { Probability of survival to } \\
\text { age } 15(n=16)\end{array}$ & .878 & $.771(.015)$ & $F=9.24(.002)$ & .357 & $17.14(.002)$ & -.780 & $-.766(.002)$ \\
\hline
\end{tabular}


Table 3. Linear regression model using survival to age 15 and life expectancy at age 15 to predict age at menarche

\begin{tabular}{|c|c|c|c|c|c|c|c|}
\hline \multirow[b]{2}{*}{ Predictor } & \multicolumn{3}{|c|}{$\begin{array}{c}\text { Whole model (including continent and } \\
\text { probability of survival to age } 15 \text { or } \\
\text { life expectancy at age 15) }\end{array}$} & \multicolumn{2}{|c|}{$\begin{array}{l}\text { Last block (change) } \\
\text { when including } \\
\text { probability of } \\
\text { survival to age } 15 \\
\text { or life expectancy } \\
\text { at age } 15 \\
\end{array}$} & \multicolumn{2}{|c|}{$\begin{array}{c}\text { Partial correlation and standardized } \\
\beta \text { coefficient (controlling } \\
\text { for continent) }\end{array}$} \\
\hline & $R$ & $R^{2}(\mathrm{SE})$ & ANOVA $(P)$ & $R_{\text {change }}^{2}$ & $F_{\text {change }}(P)$ & Partial correlation & Standardized $\beta(P)$ \\
\hline $\begin{array}{l}\text { Probability of survival to } \\
\quad \text { age } 15(n=16)\end{array}$ & .832 & $.693(.033)$ & $F=6.196(.007)$ & .073 & $2.62(.134)$ & .439 & $.324(.134)$ \\
\hline $\begin{array}{l}\text { Life expectancy at age } 15 \\
\quad(n=13)\end{array}$ & .864 & $.747(.032)$ & $F=5.915(.016)$ & .191 & $6.05(.039)$ & .656 & $.456(.039)$ \\
\hline
\end{tabular}

and continent). Using life expectancy at age 15 as a predictor of adult height slightly increases correlations $(\beta=0.642, P<$ .001 ), and an extra $33.6 \%$ of the variance is explained in relation to the basal model. This brings the total variance explained by the whole model (including continent, sex, and life expectancy at age 15 ) to $71 \%$ (table 1 ). Survival to age 15 and life expectancy at age 15 are highly correlated $(n=18, R=558, P=$ .016); however, the first expresses prereproductive survival, while the second expresses adult survival.

\section{Analysis 2: Relationship between Mortality}

Rates, Growth, and Development

This analysis investigates the relationship between probability of survival to age 15 and relative height at age 10 (percentage of adult height achieved by age 10), which is used as a proxy for growth rate (the more growth completed by age 10, the faster the growth rate). Probability of survival to age 15 is used here rather than life expectancy at age 15 because of sample size constraints. The multiple linear regression model controlling for sex and continent shows a negative association between probability of survival to age 15 and percentage of adult height achieved by age $10(n=16, \beta=-0.766, P=$ .002 ), which implies that children exposed to higher mortality environments grow at faster rates than children in lower mortality environments (table 2).

In addition, the influence of mortality rate on age at men- arche was analyzed. When probability of survival to age 15 is used as the predictor variable to assess the effect of mortality on age at menarche, the relationship is not significant because the inclusion of survival to age 15 as a predictor to the basal model (including continent) does not improve the model $\left(n=16, R_{\text {change }}^{2}=0.073, F_{\text {change }}=2.62, P=.134\right.$; table 3$)$. However, when life expectancy at age 15 is used as the independent variable, there is a significant correlation with age at menarche when continent is controlled for $(\beta=0.456$, $P=.039$; table 3$)$. Including life expectancy at age 15 as a predictor significantly improves the basal model $(n=16$, $F_{\text {change }}=6.05, P=.039$ ), explaining an extra $19.1 \%$ of the variability in age at menarche in our samples and bringing the total variability explained by the whole model to $74.7 \%$. This is a positive relationship, meaning that populations who live for longer have a later age at menarche (table 3 ).

\section{Analysis 3: Relationship between Environmental Settings and Adult Height Variation}

To test whether environmental setting has an effect on body size, we ran a multiple regression analysis controlling for sex and continent, with adult height as the dependent variable and environmental settings (savanna, forest, tundra, and desert) as predictor variables. Dummy variables are used to enter the environmental settings as predictors, as environmental settings are discrete. The inclusion of environmental settings

Table 4. Linear regression model using environmental settings (forest, savanna [S], tundra [T], and desert [D]) to predict adult height

\begin{tabular}{|c|c|c|c|c|c|c|c|}
\hline \multirow[b]{2}{*}{ Predictor } & \multicolumn{3}{|c|}{$\begin{array}{l}\text { Whole model (including sex, continent, } \\
\text { and environment) }\end{array}$} & \multicolumn{2}{|c|}{$\begin{array}{l}\text { Last block (change) } \\
\text { when including } \\
\text { environment }\end{array}$} & \multicolumn{2}{|c|}{$\begin{array}{l}\text { Partial correlation and standardized } \\
\beta \text { coefficient, forest }{ }^{\mathrm{a}} \text { as } \\
\text { reference (controlling for } \\
\text { sex and continent) }\end{array}$} \\
\hline & $R$ & $R^{2}(\mathrm{SE})$ & ANOVA $(P)$ & $R_{\text {change }}^{2}$ & $F_{\text {change }}(P)$ & Partial correlation & Standardized $\beta(P)$ \\
\hline $\begin{array}{l}\text { Environmental settings } \\
\qquad(n=150)\end{array}$ & .789 & $.622(.016)$ & $F=22.8(<.001)$ & .167 & $20.5(<.001)$ & $\begin{array}{l}\text { S, .539; D, .270; } \\
\quad \mathrm{T}, .06\end{array}$ & $\begin{array}{l}\mathrm{S}, .442(<.001) ; \mathrm{D}, \\
\quad .181(.001) ; \mathrm{T}, .089 \\
\quad(<.476)\end{array}$ \\
\hline
\end{tabular}

a Environmental settings were entered as dummy variables because "environmental settings" is a categorical variable. As such, one of the categories has to be a reference (all other categories are measured against the reference). 
Table 5. Total frequency of cases in each continent and each environmental setting

\begin{tabular}{lcccccc}
\hline Ecology & Africa & Asia & Australia & Europe & North America & South America \\
\hline Desert & 5 & 0 & 4 & 0 & 1 & 1 \\
Forest & 17 & 53 & 3 & 2 & 2 & 18 \\
Savanna & 14 & 8 & 1 & 0 & 2 & 6 \\
Tundra & 0 & 0 & 0 & 2 & 10 & 1 \\
\hline
\end{tabular}

in the last block significantly improves the basal model $\left(F_{\text {change }}=22.8, P<.001\right)$, explaining an additional $16.7 \%$ of the height variability. The complete model including sex, continent, and environment is highly significant and explains $62.2 \%$ of the variance in height $\left(n=150, R^{2}=0.622, P<\right.$ $.001)$. Controlling for sex and continent, the savanna environment has a significantly positive effect on adult height compared with the forest environment $(n=150, \beta=0.442$, $P<.001)$ and the desert environment $(n=150, \beta=0.181$, $P=.001$; table 4 ). Populations are represented from all continents, and therefore phylogenetic relationships are unlikely to explain why living in the savanna or desert is associated with greater stature than living in the forest (table 5).

\section{Analysis 4: Relationship between Environmental Setting, Mortality Rates, and Adult Height Variation}

When probability of survival to age 15 is included as a predictor variable together with the environmental settings, the general model improves $\left(n=42, R^{2}=0.700, P<.001\right)$ in spite of the much smaller sample sizes $(n=42$ vs. $n=150)$. The inclusion of probability of survival to age 15 together with environmental settings in the last block of the regression explains an additional $26.9 \%$ of the height variability in our sample. Living in the savanna remains positively associated with height compared with living in the forest even when the effect of survival to age 15 is taken into account $(n=42$, $\beta=0.387, P<.001$ ), but the contrast between living in the desert and living in the forest found previously is no longer significant $(n=42, \beta=0.115, P>.05)$. Probability of survival to age 15 is the strongest predictor of height in the model ( $n=42, \beta=0.569, P<.001$; table 6 ). The reduction of the explanatory power of the environmental factors when the probability of survival to age 15 is introduced as a predictor has to be interpreted with caution because the sample size (and therefore the representation of all environmental settings in each continent) is reduced when all variables are included (table 7).

Unfortunately, sample sizes and sample distributions are insufficient to allow height, environmental variables, and other mortality indicator variables (life expectancy at birth and life expectancy at age 15 in the same analyses) to be analyzed together. However, the results do show that the probability of survival to age 15 is a strong predictor of adult height and that living in the savanna has a more positive influence on height than living in the forest independent of the effect of mortality.

\section{Analysis 5: Relationship between Subsistence Strategies, Adult Height, and Life History Diversity}

In order to assess the effect of subsistence strategy on adult body size variation, we used data on diet composition in hunter-gatherer groups assembled by Binford (2001, table 5.01). The percentages of reliance on fishing and hunting were combined to calculate reliance on animal protein.

We use a multiple linear regression analysis with height as the dependent variable to understand the role of the per-

Table 6. Linear regression model using environmental settings (forest, savanna [S], tundra [T], and desert [D]) and probability of survival to age 15 to predict adult height

\begin{tabular}{|c|c|c|c|c|c|c|c|}
\hline \multirow[b]{2}{*}{ Predictor } & \multicolumn{3}{|c|}{$\begin{array}{l}\text { Whole model (including sex, continent, } \\
\text { environment, and probability of } \\
\text { survival to age 15) }\end{array}$} & \multicolumn{2}{|c|}{$\begin{array}{l}\text { Last block (change) } \\
\text { when including } \\
\text { survival to } \\
\text { age } 15\end{array}$} & \multicolumn{2}{|c|}{$\begin{array}{l}\text { Partial correlation and standardized } \beta \\
\text { coefficient, forest }{ }^{\mathrm{a}} \text { as reference } \\
\text { (controlling for sex, continent, } \\
\text { and environment) }\end{array}$} \\
\hline & $R$ & $R^{2}(\mathrm{SE})$ & ANOVA $(P)$ & $R_{\text {change }}^{2}$ & $F_{\text {change }}(P)$ & Partial correlation & Standardized $\beta(P)$ \\
\hline $\begin{array}{l}\text { Environmental settin } \\
\text { and survival to } \\
\text { age } 15(n=42)\end{array}$ & .836 & $.700(.015)$ & $F=7.22(<.001)$ & .269 & $27.7(<.001)$ & $\begin{array}{l}\mathrm{S}, .543 ; \mathrm{D}, .187 ; \mathrm{T} \\
\quad-.065 ; \text { probability } \\
\quad \text { of survival, } .687\end{array}$ & $\begin{array}{c}\text { S, . } 387(.001) ; \mathrm{D}, \\
\quad .115(.296) ; \mathrm{T} \\
-.106(.717) ; \\
\text { probability of } \\
\text { survival } 15 \\
.569(<.001)\end{array}$ \\
\hline
\end{tabular}

\footnotetext{
a Environmental settings were entered as dummy variables because "environmental settings" is a categorical variable. As such, one of the categories
} has to be a reference (all other categories are measured against the reference). 
Table 7. Frequency of cases in each continent and each environmental setting when only individuals with data on survival to age 15 are considered

\begin{tabular}{lcrcc}
\hline Ecology & Africa & Asia & North America & South America \\
\hline Desert & 3 & 0 & 1 & 1 \\
Forest & 9 & 10 & 2 & 18 \\
Savanna & 4 & 0 & 2 & 6 \\
Tundra & 0 & 0 & 10 & 1 \\
\hline
\end{tabular}

centage of reliance on animal protein in shaping adult height variability among hunter-gatherers, controlling for sex, continent, and environmental variables. Although the total model including sex, continent, environment, and percent reliance on animal protein is highly significant $\left(n=52, R^{2}=0.811\right.$, $P<.05)$, percent reliance on animal protein is not a significant factor in predicting height when the other variables are controlled $(n=52, \beta=0.196, P>.05$; table 8$)$.

\section{Discussion}

These results show that variation in adult height is highly influenced by mortality patterns in our worldwide sample of small-scale human populations. Preadult mortality (probability of survival to age 15) alone (when controlled by sex and continent) explains $29.9 \%$ of the variation in adult height, while adult survival (life expectancy at age 15) explains 33.6\%. The model combining life expectancy at age 15 with sex and continent explains a great proportion of the variance $(71.1 \%)$.

These results are in accordance with the predictions of life history theory (Charnov 1992). Life history theory predicts that high mortality rates should lead to relatively fast-paced life history strategies (Charnov 1992). Correspondingly, we should expect that those human populations that face higher rates of adult mortality will have individuals who, on average, develop earlier. They will achieve full growth relatively early, reproduce at an earlier age than those with relatively low mortality rates, and thereby reduce the chances of death before reproduction (Migliano 2005; Migliano, Vinicius, and Lahr 2007; Walker et al. 2006).

Our results also provide clues to the mechanisms through which mortality rates affect adult body size. According to the theory, populations under high risk of death should develop faster, achieving adult body sizes sooner, and should also mature earlier in order to start reproducing sooner. This is what we find in our analyses: populations living in higher mortality environments have earlier menarche and grow at a faster rate (as proxied by the proportion of adult body size achieved at age 10) than populations living in lower mortality environments (see tables 2, 3). This is the opposite effect observed when short stature is determined by malnourishment, where populations should achieve short stature as a result of delayed sexual and growth maturation (Migliano, Vinicius, and Lahr 2007).

As Kuzawa and Bragg (2012) have shown, developmental plasticity exerts a strong influence on age at menarche and body size (both weight and height). Populations experiencing overnutrition in the West or individuals recently adopted into Western culture have earlier menarche and earlier growth cessation and achieve larger body sizes as a consequence of decreasing nutritional constraints. The expression of this phenotype should, therefore, be interpreted as a response to an unconstrained environment (where time and resources are virtually unlimited, releasing trade-offs; fig. 1). However, this situation is virtually nonexistent in tribal populations, where both time (survivorship) and resources (calories) are limited to varying extents. Our results suggest that mortality rates have a strong influence on adult height and maturation variability in natural environment populations; although the importance of nutrition should also be considered (fig. 1; see Kuzawa and Bragg 2012, fig. 3). Our analysis of the effects of diet on height variation in a subset of the sample (the hunter-gatherers) for which data on reliance on gathering, fishing, and hunting were available did not reach significance. There was a positive correlation between a diet high in animal protein and adult stature; however, a larger sample size and better data are needed.

Finally, our results indicate that living in the savanna has a positive correlation with height compared with living in the forest irrespective of the differences observed in mortality rates. This result is found even when controlling for continent (as a way to control for phylogenetic and statistical nonindependence between populations). Other effects, such as differences in temperature, humidity, or diet undoubtedly play a role in explaining interpopulation differences in stature. Tall

Table 8. Linear regression model using environmental settings (forest, savanna, tundra, and desert) and percentage of dependence on animal protein to predict adult height

\begin{tabular}{|c|c|c|c|c|c|c|c|}
\hline \multirow[b]{2}{*}{ Predictor } & \multicolumn{3}{|c|}{$\begin{array}{l}\text { Whole model (including sex, continent, } \\
\text { environment, and percent reliance } \\
\text { on animal protein) }\end{array}$} & \multicolumn{2}{|c|}{$\begin{array}{l}\text { Last block (change) } \\
\text { when including } \\
\text { percent reliance on } \\
\text { animal protein }\end{array}$} & \multicolumn{2}{|c|}{$\begin{array}{c}\text { Partial correlation and standardized } \\
\beta \text { coefficient (controlling for } \\
\text { sex and continent) }\end{array}$} \\
\hline & $R$ & $R^{2}(\mathrm{SE})$ & ANOVA $(P)$ & $R_{\text {change }}^{2}$ & $F_{\text {change }}(P)$ & Partial correlation & Standardized $\beta(P)$ \\
\hline $\begin{array}{l}\text { Percent reliance } \\
\text { on animal protein } \\
(n=52)\end{array}$ & .901 & $.811(.0137)$ & $F=15.6(<.001)$ & .008 & $1.73(.196)$ & .204 & $.196(.196)$ \\
\hline
\end{tabular}




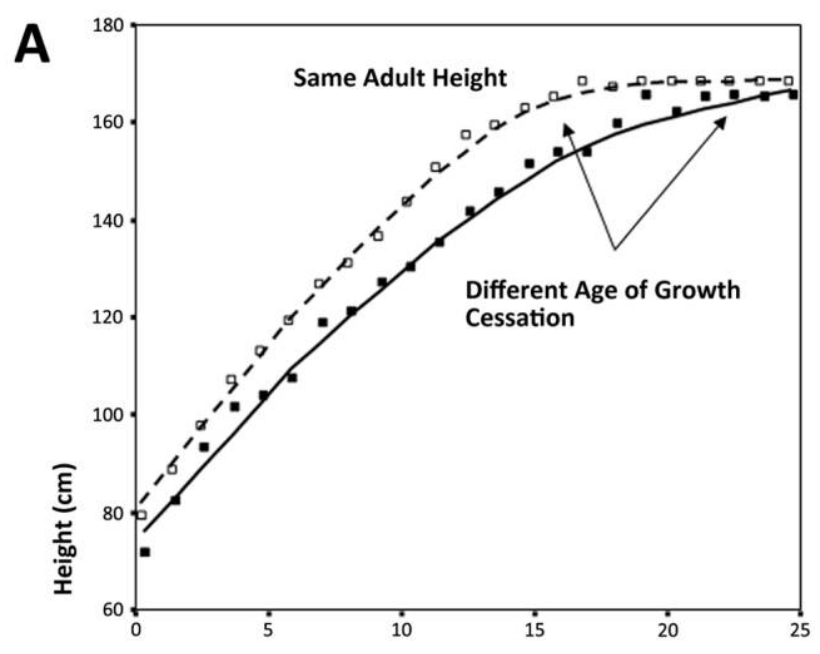

Age (year)

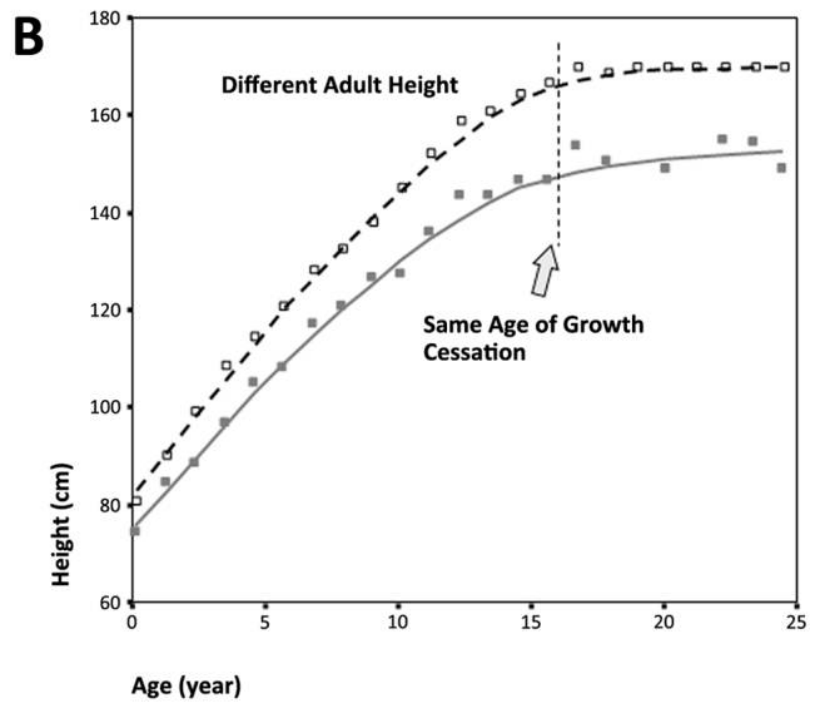

Figure 1. Interaction between nutrition and mortality rates influencing adult height. In populations with no caloric restrictions and low mortality rates, growth cessation happens relatively early (maximizing reproductive span) at larger body sizes (maximizing energy budget to be invested into reproduction), such as in the populations of the United States (National Center for Health Statistics [NCHS] data; white squares, dashed lines, NCHS 2002). $A$, In populations where nutritional stress is high and life expectancy is relatively high, such as the Turkana pastoralists (data from Little, Galvin, and Mugambi 1983; black squares), growth cessation is delayed (maximizing body size); that is, Turkana pastoralists achieve the same adult height as the well-nourished Americans-however, much later. $B$, When high mortality rates are combined with relatively poor nutrition, growth cessation cannot be delayed because reproductive life span is already impaired; thus, populations in these conditions, such as the Aeta from the Philippines (data from Migliano, Vinicius, and Lahr 2007; gray squares), have an early growth cessation (as early as the Americans) at much smaller sizes (2 SD below the American average). stature and narrow elongated bodies have long been explained as a thermoregulatory mechanism in hot savanna environments (e.g., Ruff 1993). The association between tropical forests and short human stature has also been identified, and different adaptive hypotheses have been suggested to explain it, from thermoregulatory adaptations proposing that shorter humans produce less heat in a tropical humid environment, being more efficient at cooling down (Cavalli-Sforza 1986), to easier locomotion in closed forests (Turnbull 1986) and adaptation to poor carbohydrate availability in tropical forests (Bailey and Peacock 1988). Small body size in forested environments is also seen in other mammals. For example, forest elephants have been estimated to be $35 \%-40 \%$ smaller in stature than their savanna counterparts (Morgan and Lee 2003), and the pygmy hippopotamus is found mainly in Liberia and only in thick forests (Eltringham 1999). More data are necessary to test whether these other variables explain part of the variance not captured by differences in mortality rates and to understand how mortality rates interact (or are influenced) by these other pressures.

\section{Applications to Hominin Evolutionary History}

Body size increase is one of the main features distinguishing the australopiths from early Homo and early Homo from Homo erectus (Antón 2012; Holliday 2012; Pontzer 2012). For early Homo, height and weight can be approximately estimated for KNM-ER 3735, OH 62, KNM-ER 1472, and 1481. The height range is $118-149 \mathrm{~cm}$ (Antón 2012), and average weight is $50-54 \mathrm{~kg}$ (Holliday 2012). This represents a $30 \%$ increase over the condition in Australopithecus (Antón 2012; Holliday 2012; Pontzer 2012). With the appearance of $H$. erectus there was an additional increase in body size of comparable magnitude (Antón 2012).

When comparing the variability in body size in modern humans to early Homo and H. erectus, it is clear that H. erectus height overlaps with the recent human range, while the early Homo variation falls below recent human variation (fig. 2A). In contrast, inferred weight variation falls well within the human range for early and late Homo (fig. 2B). This pattern indicates important stature/weight differences between early Homo and living humans, implying differences in body proportions (see Holliday 2012).

In $H$. erectus the range of body size variation $(40-68 \mathrm{~kg}$, $146-185 \mathrm{~cm}$ ) falls well within the interpopulation variation observed in modern humans (fig. 2; Antón 2012). Moreover, Georgian specimens have ranges of size overlapping the intrapopulation variation observed in Philippine Pygmies (fig. 2). Although there is great variation in body size within $H$. erectus, the similarities with modern human ranges indicate that perhaps the same patterns of diversification apply to the two groups. Therefore, we suggest that understanding the causes of body size variation in living human populations is relevant to interpreting the variation observed within Homo and in particular within $H$. erectus. 

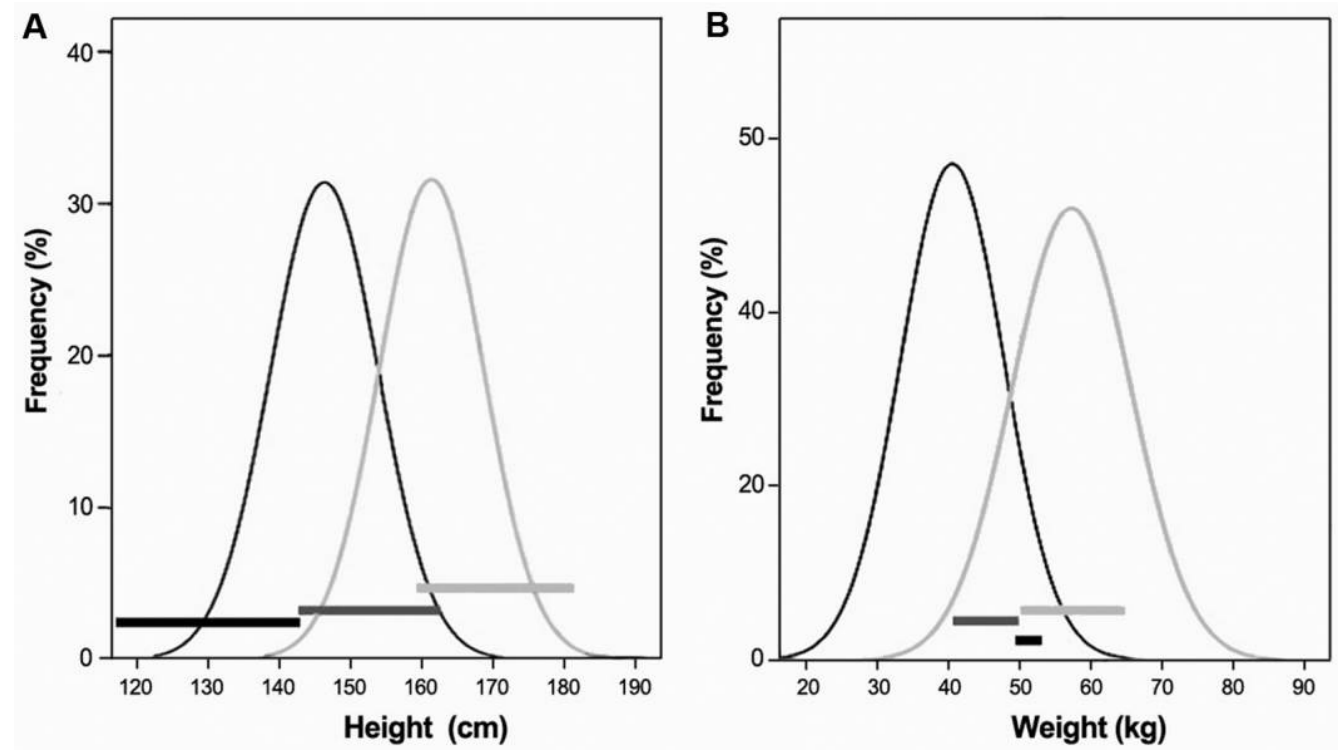

Figure 2. A, Distribution of height across 3,263 small-scale world population averages (gray) and within Aeta Pygmies from the Philippines (black; $n=348$ ). The thick black line is the range of height variation in early Homo, while the thick dark gray line is the range of height variation in Homo erectus (Georgian specimens), and the thick light gray line is the range of height variation in $H$. erectus (African specimens). B, Distribution of weight across 249 small-scale world population averages (gray) and within Aeta Pygmies from the Philippines (black; $n=348$ ). The thick black line is the range of weight variation in early Homo, while the thick dark gray line is the range of weight variation in H. erectus (Georgian specimens), and the thick light gray line is the range of weight variation in $H$. erectus (African specimens). Human variation from Kings Diversity Project (M. M. Lahr and R. Foley, unpublished data); Aeta Pygmy data (Philippines) from Migliano (2005); and hominin data from Antón (2012).

Our results indicate that two factors could have been associated with the stature variation observed both between and within hominin taxa. The first is variation in preadult and adult mortality rates, and the second is occupation of different environments. Although diet was not significant in our analyses, we know from studies of modern human populations that it also could be a relevant factor (e.g., Kuzawa and Bragg 2012).

Testing the distinct influences of at least mortality rate and nutrition on observed body size in the fossil record may be possible to achieve. The results of this study and of others (Kuzawa and Bragg 2012; Migliano, Vinicius, and Lahr 2007; Walker et al. 2006) indicate that poor nutrition and high mortality rates both lead to short stature but through different mechanisms: poor nutrition should lead to delayed growth and maturation (due to the lack of resources), while high mortality rates should lead to early development and maturation (due to selection for early reproduction). Understanding how closely the pace of tooth development and the sequence and timing of dental eruption match the pace of life history in current and extinct populations (Dean 2006; Schwartz 2012) would help immensely with understanding the causes behind body size variation in Homo. For example, if the short stature of Homo floresiensis (Brown et al. 2004) and $H$. erectus in Georgia (aka Homo georgicus; Lordkipanidze et al. 2007) were a consequence of nutritional insufficiency, we would expect lower rates of growth and development in relation to larger $H$. erectus specimens. On the other hand, if differences were due to differing mortality environments, we would expect the smaller specimens to have a more rapid life history pace (as proxied by their patterns of tooth development).

Although the data are not yet available to test the relationship of nutrition and mortality rate on hominin stature and the relationship of these variables to the third complicating factor, environment, it is interesting to speculate on the implications of these factors to the evolution of Homo. If mortality rate does prove to be a significant factor associated with hominin stature as our analyses suggest, it would imply that early Homo had a reduced mortality rate in relation to the australopiths and that $H$. erectus had further reduced its mortality rate in relation to early Homo. The question then is how the hominins achieved reduced mortality rates in the context of an increasingly variable environment and expansion into a broader range of niches (Potts 2012). Potts argues that greater behavioral flexibility associated with a larger brain size together with the capacity to extract more effectively protein and fat resources and an increased capacity for avoiding predation might have contributed to the reduction of mortality rates (see also Antón and Snodgrass 2012; Kaplan et al. 2000).

Important factors undoubtedly include subsistence shifts 
and predator avoidance but would also include other cultural adaptations as well as opportunities for cooperation, alloparenting, parental investment, and increased child provisioning (Bribiescas, Ellison, and Gray 2012; Isler and van Schaik 2012). The importance of cooperation in early Homo and $H$. erectus also would be in agreement with a number of other lines of reasoning. For example, without an increase in cooperative social behavior to help reduce interbirth intervals, energetic demands on $H$. erectus females would likely have been unmanageable (Aiello and Key 2002). The "gray ceiling hypothesis" also argues that the larger brain size found in early Homo and H. erectus would not be possible without alloparenting and other forms of cooperative behavior (Isler and van Schaik 2012). Furthermore, Pontzer (2012) argues that the larger home-range size implied by the larger body sizes characteristic of Homo would necessitate a high-throughput dietary strategy (increased daily energy expenditure) and greater reproductive investment resulting in an increased lifetime reproductive output. He suggests that this would necessitate greater food availability perhaps facilitated through food sharing and increased cooperative behavior.

Our analyses suggest that the effect of survival on body size variation seems to be stronger than the influence of environmental settings or diet on adult stature within a species. The implication is that adapting to a particular climatic setting might be a less important factor in relation to stature increase than reducing mortality rates. Humans rely on behavioral and cultural plasticity to adapt to different climatic settings, and this might also have been the case for Homo and especially H. erectus (Potts 2012). It is probable that certain groups of early Homo were more successful than others in buffering environmental pressures, leading to differences in extrinsic mortality rates and consequently in body size.

Uncovering the particular reasons as well as estimating the relative influence of extrinsic mortality rates, diet, and environmental setting in shaping this diversity will require a close comparative look at behavioral adaptations, resource exploration, predation, and competition in these groups. It is a challenge for future research.

\section{Acknowledgments}

We are grateful to Leslie Aiello and Susan Antón, with assistance from Laurie Obbink, for organizing the Wenner-Gren symposium in Sintra, Portugal, and to all participants in the symposium for insightful comments. We thank Lucio Vinicius, Rodolph Schlaepfer, Ruth Mace, Tom Currie, and the Human Evolutionary Ecology Research Group at University College London for useful comments.

\section{References Cited}

Adair, Linda S. 2007. Size at birth and growth trajectories to young adulthood. American Journal of Human Biology 19(3):327-337.
Aiello, Leslie C., and Catherine Key. 2002. Energetic consequences of being a Homo erectus female. American Journal of Human Biology 14(5):551-565. Aiello, Leslie C., and Peter Wheeler. 1995. The expensive-tissue hypothesis: the brain and the digestive system in human and primate evolution. Current Anthropology 36:199-221.

Akachi, Yoko, and David Canning. 2007. The height of women in sub-Saharan Africa: the role of health, nutrition, and income in childhood. Annals of Human Biology 34(4):397-410.

Antón, Susan C. 2012. Early Homo: who, when, and where. Current Anthropology 53(suppl. 6):S278-S298.

Antón, Susan C., and J. Josh Snodgrass. 2012. Origin and evolution of genus Homo: a new perspective. Current Anthropology 53(suppl. 6):S479-S496.

Ashton, Kyle G., Mark C. Tracy, and Alan de Queiroz. 2000. Is Bergmann's rule valid for mammals? American Naturalist 156:390-415.

Bailey, Robert C. 1991. The comparative growth of Efe Pygmies and African farmers from birth to age 5 years. Annals of Human Biology 18:113-120.

Bailey, Robert C., and Nadine R. Peacock. 1988. Efe Pygmies of northeast Zaire subsistence strategies in the Ituri Forest. In Coping with uncertainty in food supply. Igor de Garine and Geoffrey Ainsworth Harrison, eds. Pp. 88-117. Oxford: Oxford University Press.

Bergmann, Karl Georg Lucas Christian. 1847. Über die Verhältnisse der Wärmeökonomie der Thiere zuihrer Grösse. Göttinger Studien 3(1):595-708.

Binford, Lewis Roberts. 2001. Constructing frames of reference: an analytical method for archaeological theory building using hunter-gatherer and environmental data sets. Berkeley: University of California Press.

Bribiescas, Richard G., Peter T. Ellison, and Peter B. Gray. 2012. Reproductive effort and paternal investment plasticity in men: implications for the evolution of Homo. Current Anthropology 53(suppl. 6):S424-S435.

Brown, Peter, Thomas Sutikna, Michael J. Morwood, Raden P. Soejono, Jatmiko, E. Wayhu Saptomo, and Rokus Awe Due. 2004. A new small-bodied hominin from the Late Pleistocene of Flores, Indonesia. Nature 431(7012): 1055-1061.

Cameron, Noel. 1991. Human growth, nutrition, and health-status in subSaharan Africa. Yearbook of Physical Anthropology 34:211-250.

Carmody, Rachel N., and Richard W. Wrangham. 2009. The energetic significance of cooking. Lournal of Human Evolution 57:379-391.

Cavalli-Sforza, Luigi Lucca. 1986. African Pygmies. Orlando, FL: Academic Press.

Charnov, Eric L. 1992. Life history invariants. Oxford: Oxford University Press. Danubio, Marica, and Emanuele Sanna. 2008. Secular changes in human biological variables in Western countries: an updated review and synthesis. Journal of Anthropological Sciences 86:91-112.

Dean, M. Christopher. 2006. Tooth microstructure tracks the pace of human life-history evolution. Proceedings of the Royal Society B 273(1603):27992808.

Eltringham, S. Keith. 1999. The hippos: natural history and conservation. London: Academic Press.

Golden, Michael H. N. 1991. The nature of nutritional deficiency in relation to growth failure and poverty. Acta Paediatrica 80:95-110.

Harvey, Paul H., and Timothy H. Clutton-Brock. 1985. Life-history variation in primates. Evolution 39(3):559-581.

Harvey, Paul H., and Andy Purvis. 1999. Understanding the ecological and evolutionary reasons for life history variation: mammals as a case study. In Advanced ecological theory: principles and applications. Jacqueline M. McGlade, ed. Pp. 232-248. Oxford: Blackwell Science.

Harvey, Paul H., and Richard M. Zammuto. 1985. Patterns of mortality and age at first reproduction in natural populations of mammals. Nature 315: 319-320.

Holliday, Trenton W. 2012. Body size, body shape, and the circumscription of the genus Homo. Current Anthropology 53(suppl. 6):S330-S345.

Isler, Karin, and Carel P. van Schaik. 2012. How our ancestors broke through the gray ceiling: comparative evidence for cooperative breeding in early Homo. Current Anthropology 53(suppl. 6):S453-S465.

Kaplan, Hillard, Kim Hill, Jane Lancaster, and A. Magdalena Hurtado. 2000. A theory of human life history evolution: diet, intelligence, and longevity. Evolutionary Anthropology 9(4):156-185.

Kuzawa, Christopher W., and Jared M. Bragg. 2012. Plasticity in human life history strategy: implications for contemporary human variation and the evolution of genus Homo. Current Anthropology 53(suppl. 6):S369-S382.

Lampl, Michelle, Francis E. Johnston, and Laurence A. Malcolm. 1978. The effects of protein supplementation on the growth and skeletal maturation of New Guinean school children. Annals of Human Biology 5:219-227.

Little, Michael A., Kathleen A. Galvin, and Mutuma Mugambi. 1983. Cross- 
sectional growth of nomadic Turkana pastoralists. Human Biology 55:811830.

Lordkipanidze, David, Tea Jashashvili, Abesalom Vekua, Marcia S. Ponce de León, Christoph P. E. Zollikofer, G. Philip Rightmire, Herman Pontzer, et al. 2007. Postcranial evidence from early Homo from Dmanisi, Georgia. Nature 449:305-310.

Migliano, Andrea Bamberg. 2005. Why Pygmies are small: ontogenetic implications of life history evolution. $\mathrm{PhD}$ thesis, University of Cambridge.

Migliano, Andrea Bamberg, Lucio Vinicius, and Marta Mirazón Lahr. 2007. Life-history trade-offs explain the evolution of human Pygmies. Proceedings of the National Academy of Sciences of the USA 104:20216-20219.

. 2010. Why are Pygmies so short? a defence of Migliano's hypothesis. Human Biology 82:109-113.

Morgan, Bethan J., and Phyllis C. Lee. 2003. Forest elephant (Loxodonta africana cyclotis) stature in the Reserve de Faune du Petit Loango. Gabon Journal of Zoology 259:337-344.

O'Connell, James F., Kristin Hawkes, and Nicholas G. Blurton Jones. 1999. Grandmothering and the evolution of Homo erectus. Lournal of Human Evolution 36:461-485.

Passey, Benjamin H., Naomi E. Levin, Thure E. Cerling, Francis H. Brown, and John M. Eiler. 2010. High-temperature environments of human evolution in East Africa based on bond ordering in paleosol carbonates. Proceedings of the National Academy of Sciences of the USA 107:11245-11249.

Pontzer, Herman. 2012. Ecological energetics in early Homo. Current Anthropology 53(suppl. 6):S346-S358.

Potts, Richard. 2012. An African environmental framework for investigating the evolution of early Homo. Current Anthropology 53(suppl. 6):S299-S317.

Promislow, Daniel E. L., and Paul H. Harvey. 1990. Living fast and dying young: a comparative analysis of life-history variation among mammals. Journal of Zoology 220:417-437.
Roberts, Derek Frank. 1973. Climate and human variability. California: Cummings.

Ruff, Christopher B. 1993. Climatic adaptation and hominid evolution: the thermoregulatory imperative. Evolutionary Anthropology 2:53-60.

Schwartz, Gary T. 2012. Growth, development, and life history throughout the evolution of Homo. Current Anthropology 53(suppl. 6):S395-S408.

Silventoinen, Karri. 2003. Determinants of variation in adult body height. Journal of Biosocial Science 35(2):263-285.

Stearns, Stephen C. 1992. The evolution of life histories. New York: Oxford University Press.

Stock, Jay T., and Andrea Bamberg Migliano. 2009. Stature, mortality, and life history among indigenous populations of the Andaman Islands, 18711986. Current Anthropology 50(5):713-725.

Trauth, Martin H., Mark A. Maslin, Alan L. Deino, Annett Junginger, Moses Lesoloyia, Eric O. Odada, Daniel O. Olago, Lydia A. Olaka, Manfred R. Strecker, and Ralph Tiedemann. 2010. Human evolution in a variable environment: the amplifier lakes of eastern Africa. Quaternary Science Reviews 29:2981-2988.

Turnbull, Colin M. 1986. Survival factors among Mbuti and other hunters of the equatorial African rain forest. In African Pygmies. Luigi L. Cavalli-Sforza, ed. Pp. 103-123. Orlando, FL: Academic Press.

Vrba, Elizabeth S. 1996. Climate, heterochrony, and human evolution. of Anthropological Research 52(1):1-28.

Walker, Robert, Michael Gurven, Kim Hill, Andrea Migliano, Napoleon Chagnon, Roberta De Souza, Gradimir Djurovic, et al. 2006. Growth rates and life histories in twenty-two small-scale societies. American Journal of Human Biology 18(3):295-311.

Wheeler, Peter E. 1992. The thermoregulatory advantages of large body size for hominids foraging in savannah environments. Journal of Human Evolution 23:351-362. 